\begin{tabular}{r|ll} 
AL-ISHLAH & Volume & $: 18$ \\
Jurnal Pendidikan Islam & Nomor & $: 1$ \\
Tahun & $: 2020$ \\
\hline
\end{tabular}

\title{
Arah Pendidikan Islam dan Penetrasi Ideologi Non Islam
}

\author{
Muhammad Saleh \\ Institut Agama Islam Negeri Parepare \\ email: m.salehwr3@gmail.com
}

\begin{abstract}
Islamic education is transformed by massive interactions by various global ideologies. This massive interaction has transformed various values and ideologies such as capitalism, secularism, liberalism, and so on, which can reduce authentic values and ideologies of Islamic teachings. Islamic education as a forum to maintain the originality and continuity of authentic Islamic doctrine, is expected to carry out reforms in terms of systems, orientation, and operations. Islamic education with the institutional managerial paradigm reconstruction is expected to exist and survive in the midst of globalization. Islamic education is important to build on the principle of monotheism, develop the values of moral mercy, uphold scientific epistemology, while still referring to the normative sources of Islam, namely the Koran and Hadith. In the midst of disruption of social order due to the acceleration of science and technology, Islamic education can be an instrument in maintaining prophetic mission in calling for Islam as rahmatan lil 'alamin.
\end{abstract}

Keywords: Islamic education, ideology, authentic, survive. 


\begin{abstract}
Abstrak
Pendidikan Islam mengalami transformasi oleh adanya interaksi massif oleh berbagai ideologi global. Interaksi massif tersebut telah menetrasikan berbagai nilai dan ideology seperti kapitalisme, sekularisme, liberalisme, dan seterusnya, yang dapat mereduksi nilai dan ideologi otentik ajaran Islam. Pendidikan Islam sebagai wadah menjaga orisinalitas dan kontiniunitas doktrin Islam secara otentik, diharapkan dapat melakukan reformasi dari segi sistem, orientasi, dan operasionalnya. Pendidikan Islam dengan rekonstruksi paradigma manajerial institusi diharapkan dapat eksis dan survive di tengah globalisasi. Pendidikan Islam penting dibangun atas prinsip ketauhidan, mengembangkan nilai-nilai akhlakul karimah, menjunjung tinggi epistemologi keilmuan, dengan tetap mengacu kepada sumber normative Islam, yakni Al-Quran dan Hadis. Di tengah disrupsi tatanan social akibat akselerasi ilmu pengetahuan dan teknologi, pendidikan Islam dapat menjadi instrument dalam menjaga misi profetik dalam menyerukan Islam sebagai rahmatan lil 'alamin.
\end{abstract}

Kata kunci: pendidikan Islam, ideology, otentik, survive.

\title{
PENDAHULUAN
}

Dalam upaya merekonstruksi kebangkitan suatu masyarakat, negara, bahkan peradaban umat manusia, keberadaan ideologi merupakan salah satu aspek penting yang menentukan kebangkitan dan pembentukan peradaban tersebut. Saat ini kehidupan kaum muslimin di berbagai negeri tengah didera oleh ideologi kapitalisme maupun sosialisme-komunisme, tidak terkecuali dengan Indonesia. Selain itu, berbagai permasalahan fundamental yang dialami oleh dunia pendidikan yang termasuk masalah globalisasi, 
demokratisasi, dan liberalisasi. ${ }^{1}$ Infiltrasi ideologi global dalam dunia pendidikan Islam sebagai bagian dari pergulatan epistemologi agar tetap survive di era kontemporer.

Era globalisasi telah menjadi sebuah realitas yang harus dihadapi oleh masyarakat dan bangsa Indonesia. Telah menjadi rahasia umum, bahwa pendidikan Islam berada pada tataran keterpurukan meskipun kemajuan di bidang pendidikan sangat pesat. ${ }^{2}$ Atas nama modernisasi, sistem pendidikan Barat telah banyak diserap dan dipakai di lembaga formal pendidikan di Negara Islam, termasuk Indonesia, tanpa memperhatikan kebajikan orisinilnya. $^{3}$ Penerimaan system pendidikan Barat tanpa selektif dapat mereduksi otentisitas sistem pendidikan Islam

Bagi semua umat manusia, pendidikan merupakan persoalan penting dalam hidup dan kehidupan. Pendidikan selalu menjadi tumpuan harapan untuk mengembangkan individu dan masyarakat. ${ }^{4}$ Pendidikan merupakan wahana, sarana, dan proses, serta alat untuk mentransfer warisan umat dari nenek moyang kepada anak cucu dan dari orang tua kepada anak. ${ }^{5}$ Pendidikan menjadi instrumen dalam menjaga kelangsungan budaya dan kearifan lokal, dan menjadi 'benteng' terhadap eksistensi ideologi Islam yang penting untuk dijaga dan dipertahankan.

Pendidikan Islam mau tidak mau terlibat di dalamnya dan dituntut untuk mampu memberikan kontribusi yang signifikan. Ia menjadi prioritas

\footnotetext{
${ }^{1}$ Anwar Sewang, and Abdul Halik. "Learning Management Model of Islamic Education based on Problem: A Case Study of the Tarbiyah and Adab Department of IAIN Parepare." Journal of Talent Development and Excellence 12.1 (2020): 2731-2747.

2Usri, Usri. "Kontribusi Pendidikan Islam Menuju Indonesia Maju." ALISHLAH: Jurnal Pendidikan Islam 17.2 (2019): 201-216.

${ }^{3}$ Affandi Mochtar, "Pendidikan Islam: Makna, Problem, dan Solusi", dalam Alef Theria Wasim, dkk (ed), Harmoni Kehidupan Beragama: Problem, Praktik dan Pendidikan, (Yogyakarta: Oasis Publisher, 2005), hal. 234

${ }^{4}$ Abdul Halik, "Paradigm of Islamic Education in the Future: The Integration of Islamic Boarding School and Favorite School." Information Management and Business Review 8.4 (2016): 24-32.

5 Hery Noer Aly dan Munzier Suparta, Pendidikan Islam Kini dan Mendatang, cet.I, (Jakarta: CV. Triasco, 2003), hal. 4-5
} 
utama untuk dilaksanakan sebab sampai saat ini masyarakat muslim sangat terbelakang di bidang pendidikan. Dengan demikian salah satu target yang harus diusahakan semaksimal mungkin adalah revitalisasi pelaksanaan pendidikan bagi umat Islam melalui cara-cara yang sesuai dengan nilai-nilai dan motif ajaran Islam sehingga tidak salah arah dengan pelaksanaan pendidikan ala Barat. Untuk menyikapinya diperlukan penyusunan sistem pendidikan yang berakar pada nilai-nilai, prinsip-prinsip dan tujuan-tujuan Islam. ${ }^{6}$

Berdasarkan dari uraian tersebut di atas, maka yang menjadi permasalahan utama dalam penelitian ini adalah bagaimana arah dan orientasi pendidikan Islam di Indonesia di tengah hegemoni ideology global dan bagaimana penetrasi ideologi global yang dominan terhadap dunia pendidikan Islam.

\section{METODE PENELITIAN}

Penelitian ini menggunakan metode penelitian kepustakaan (library research), yaitu penelitian yang dilaksanakan dengan menggunakan literatur (kepustakaan), baik berupa buku, catatan, maupun laporan hasil penelitian terdahulu. ${ }^{7}$ Jenis penelitian ini adalah deskriptif yang berciri historis, ${ }^{8}$ yaitu usaha untuk membuat pencandraan secara sistematis, faktual dan akurat mengenai fakta-fakta dan sifat-sifat populasi atau daerah tertentu ${ }^{9}$, historisnya adalah karena memiliki cirri dimensi sejarah, kronologis proses

6 Suprayetno, "Modernisasi Sistem Pendidikan Pesantren sebagai Kebutuhan Masyarakat", dalam Dody S. Truna dan Ismatu Ropi, Pranata Islam di Indonesia: Pergulatan Sosial, Politik, Hukum, dan Pendidikan (Cet.I; Ciputat: Logos Wacana llmu, 2002), h. 273.

${ }^{7}$ Iqbal Hasan, Analisis Data Penelitian Dengan Statistik (Jakarta: Bumi Aksara, 2008), h. 5.

${ }^{8}$ Kaelan, Metode Penelitian Agama Kualitatif Interdisipliner (Yogyakarta: Paradigma, 2010), 134.

${ }^{9}$ Sumadi Suryabrata, Metodologi Penelitian (Jakarta: PT. Raja Grafindo Persada, cet. Ke-11, 1998), h. 18. 
interaksi dan penetrasi antara ideology global dan ideology Islam di Indonesia. Sumber data dalam penelitian ini, terdiri atas sumber data primer dan sekunder. Sumber data primer meliputi literature yang terkait langsung dengan subjek penelitian, bidang sejarah pendidikan Islam, ilmu pendidikan Islam, filsafat pendidikan Islam, sistem pendidikan Islam di Indonesia, sednagkan sumber data sekunder adalah literature pendukung baik berupa sejarah Indonesia secara umum, sejarah pendidikan umum, dokumen Negara, regulasi pendidikan, dan seterusnya. Metode mengelolah data dilakukan dengan tahap editing, Classifaying, Verifying, Analyzing, dan Concluding. ${ }^{10}$ Kemudian, analisis data dilakukan secara deskriptif, yaitu penelitian yang berusaha mendeskripsikan suatu gejala, peristiwa, kejadian yang terjadi saat sekarang. ${ }^{11}$

\section{Hasil Penelitian}

\section{Arah Pendidikan Islam di Indonesia}

Pendidikan Islam adalah bimbingan jasmani dan rohani menuju terbentuknya kepribadian utama menurut ukuran-ukuran Islam. Dengan pengertian lain, pendidikan Islam merupakan suatu bentuk kepribadian utama yakni kepribadian muslim. Kepribadian yang memiliki nilai-nilai agama Islam, memilih dan memutuskan serta berbuat berdasarkan nilai-nilai Islam, dan bertanggung jawab sesuai dengan nilai-nilai Islam. Pendidikan Islam merupakan pendidikan yang bertujuan membentuk individu menjadi makhluk yang bercorak diri, berderajat tinggi menurut ukuran Allah dan isi pendidikannya adalah mewujudkan tujuan ajaran Allah. ${ }^{12}$

\footnotetext{
1998), h. 86.

${ }^{10}$ Kartini Kartono, Pengantar Metodologi Research (Bandung: ALUMNI, ${ }^{11}$ Juliansyah Noor, Metode Penelitian: Skripsi, Tesis, Desertasi, dan Karya Ilmiah (Jakarta: Kencana, 2011), h. 34.

12 Abdullah Idi dan Suharto, Toto, Revitalisasi Pendidikan Islam, (Yogyakarta: Tiara Wacana, 2006), h. 9
}

AL-ISHLAH: Jurnal Pendidikan Islam

Volume 18, Nomor 1, Juni 2020

P-ISSN : 2685-6581; E-ISSN : 1693-7449 
Pendidikan Islam adalah sistem pendidikan yang dapat memberikan kemampuan seseorang untuk memimpin kehidupannya, sesuai dengan citacita Islam, karena nilai-nilai Islam telah menjiwai dan mewarnai corak kepribadiannya. ${ }^{13}$ Pendidikan Islam bila dilihat dari segi kehidupan kultural umat manusia tidak lain adalah merupakan salah satu alat pembudayaan (enkulturasi) masyarakat manusia itu sendiri. Pendidikan Islam adalah proses membimbing dan mengarahkan pertumbuhan serta perkembangan anak didik agar menjadi manusia dewasa. ${ }^{14}$

Sedangkan menurut Zakiah Daradjat, pendidikan Islam adalah sebagai suatu bentuk perbaikan sikap mental yang akan terwujud dalam amal perbuatan, baik bagi keperluan diri sendiri maupun orang lain, dan bukan sekedar bersifat teoritis akan tetapi juga praktis, serta merupakan suatu kolaborasi antara pendidikan iman dan pendidikan amal. ${ }^{15}$

Karel Steenbrink, menyatakan bahwa keberadaan pendidikan Islam di Indonesia cukup variatif. Steenbrink mengkategori pendidikan tersebut dalam tiga jenis, yaitu pendidikan Islam yang berbasis pada pondok pesentren, madrasah dan sekolah. Ketiga jenis pendidikan ini diharapkan menjadi "modal" dalam upaya mengintegrasikan ilmu pengetahuan sebagai suatu paradigma didaktik-metodologis. Sebab, pengembangan keilmuan yang integral (interdisipliner) akan mampu menjawab kesan dikotomis dalam lembaga pendidikan Islam selama ini berkembang. ${ }^{16}$

Pada sisi lain, muncul pula jenis pendidikan luar sekolah bagi anakanak muslim dengan model pesantrenisasi dan TPA (Taman Pendidikan al-

\footnotetext{
${ }^{13}$ Abdul Halik, "Dialektika Filsafat Pendidikan Islam (Argumentasi dan Psikologi)." Istiqra' 1.1 (2013): 22-28.

${ }^{14}$ M. Arifin, Kapita selekta Pendidikan (Islam dan Umum), (Jakarta: Bumi Aksara, 2000), h. 10-16 28

${ }^{15}$ Zakiah Daradjat, IImu Pendidikan Islam, (Jakarta: Bumi Aksara, 2000), h.

${ }^{16}$ Karel A. Steenbrink, Pesantren Madrasah Sekolah Pendidikan Islam dalam Kurun Moderen, Cet. Kedua, (Jakarta: LP3ES, 1994), h. 25
} 
Qur'an). Pendidikan pesantrenisasi sebagai jenis pendidikan Islam yang muncul sebagai kekuatan pendidikan Islam, walaupun dilaksanakan secara insidental pada setiap bulan Ramadhan, tetapi terencana dan terprogram oleh sekolah-sekolah. Tetapi sayangnya pendidikan model ini belum ditindak lanjuti dan dievaluasi efektitas dan efisiensi prosesnya, baik dari kurikulum dan materi, metode, pengajar, waktu pelaksanaan dan organisasi.

Perkembangan yang mencolok pada tahun 90 -an adalah munculnya sekolah-sekolah elite Muslim yang dikenal sebagai "sekolah Islam". Sekolah-sekolah itu mulai menyatakan dirinya secara formal dan diakui oleh banyak kaum Muslim sebagai "sekolah unggulan" atau "sekolah Islam unggulan". Sekolah-sekolah tersebut dapat dikatakan sebagai "sekolah elite" Islam, karena sejumlah alasan yang mendasarinya. ${ }^{17}$

Alasan pertama bahwa sekolah-sekolah tersebut bersifat elite dari sudut akademis, dalam beberapa kasus hanya siswa-siswa terbaik yang dapat diterima sekolah-sekolah tersebut melalui seleksi yang kompetitif. Guru-guru yang mengajar di sekolah tersebut hanyalah mereka yang memenuhi persyaratan yang dapat diterima dan melalui seleksi secara kompetetif. Sekolah-sekolah tersebut dikelolah dengan manajemen yang baik dengan memiliki berbagai sarana pendidikan yang jauh lebih baik dan lebih lengkap, seperti perpustakaan, laboratorium, bengkel kerja, ruang komputer, masjid dan sarana olahraga. Semua itu membuat peserta didik di sekolah-sekolah tersebut jauh lebih baik secara akademis bila dibandingkan dengan sekolah-sekolah Islam lainnya dan bahkan dengan sekolah umum yang disekolah oleh pemerintah.

Dari perkembangan sekolah-sekolah ini, pemerintah dalam hal ini Kementerian Agama dan para ahli pendidikan Islam mulai percaya bahwa kualitas pendidikan madrasah dapat ditingkatkan, artinya bahwa pendidikan berkualitas yang ditawarkan madrasah akan dapat "dibeli" oleh kalangan

${ }^{17}$ Azyumardi Azra, Pendidikan Islam Tradisi dan Modernisasi Menuju Milennium Baru, (Jakarta: Logo Wacana IImu, 1999), hal. 67 
orang tua Muslim. Maka tampaknya, harus dilakukan koreksi secara cepat dan cermat tentang program-program pendidikan Islam yang sedang dijalankan, sehingga perbedaan antara pendidikan Islam dengan pendidikan umum dalam konfigurasi pendidikan nasional dapat dipersempit.

Artinya, secara kualitas pendidikan Islam harus mendapat kesempatan yang luas dan seimbang dengan umatnya yang besar di bumi Indonesia ini. Bila menginginkan pendidikan Islam dapat bersaing dengan pendidikan lain, tentu saja persoalan visi, misi, tujuan, fungsi, metode, materi dan kurikulum, orientasi, manajemen dan organisasi pendidikan Islam, harus dikoreksi, direvisi dan bahkan direadaptasi. Pendidikan Islam akan menjadi pendidikan yang menarik minat peserta didik tanpa mengurangi prinsip-prinsip ajaran dari sumber pokok Islam yaitu al-Qur'an dan Hadis.

Apabila persoalan tersebut dilakukan secara baik, terencana dan terprogram, pendidikan Islam akan menjadi lebih solid dalam memberdayakan umat Islam di Indonesia dan siap menghadapi tantangan globalisasi serta tantangan reformasi di berbagai bidang kehidupan berupa demokrasi pendidikan, membangun etos kerja, profesionalisme, memiliki kemampuan emosional dan moralitas agar dapat membangun masa depan yang lebih baik, lebih maju, damai, adil dan lebih sejahtera, sehingga terwujud masyarakat baru Indonesia yang rahmatan lil'alamin.

Dalam upaya mencari pola atau model alternatif pendidikan Islam di Indonesia, hendaknya pengembangan pendidikan Islam menitikberatkan atau berorientasi kepada visi dan misi, fleksibilitas, relevansi pendidikan di sekolah (formal) dan pendidikan di luar sekolah (non formal). Artinya keluwesan sistem dan kerjasama antara bentuk lembaga pendidikan Islam itu, akan melahirkan model alternatif baru dewasa ini dan masa mendatang. Dalam upaya mencari "model alternatif pendidikan Islam" yang akan disesuaikan dengan kebutuhan masyarakat Indonesia, paling tidak ada tiga pendekatan yang ditawarkan sebagai pola alternatif pendidikan Islam, yaitu:

1. Pendekatan sistemik, yaitu perubahan harus dilakukan terhadap keseluruhan sistem pada lembaga pendidikan Islam formal yang ada, 
dalam arti terjadi perubahan total.

2. Pendekatan suplementer, yaitu dengan menambah sejumlah paket pendidikan yang bertujuan memperluas pemahaman dan penghayatan ajaran Islam secara lebih memadai. Langkah ini yang dilakukan dengan istilah yang populer adalah "tambal sulam".

3. Pendekatan komplementer, yaitu dengan upaya mengubah kurikulum dengan sedikit radikal untuk disesuaikan secara terpadu. Artinya, untuk kondisi sekarang ini, perubahan kurikulum pendidikan Islam harus diorientasikan pada kompetensi yaitu kompetensi knowledge (pengetahuan), skill (keterampilan), kompetensi ability (kemampuan tertentu), kompetensi sosial-kultural, dan kompetensi spiritual ilahiyah. ${ }^{18}$

\section{Penetrasi Ideologi Non Islam Terhadap Pendidikan Islam}

Pendidikan Islam di Indonesia merupakan warisan peradaban Islam dan sekaligus aset bagi pembangunan pendidikan nasional, serta sebagai amanat sejarah untuk dipelihara dan dikembangkan oleh umat Islam dari masa kemasa. Sejalan dengan proses penyebaran Islam di Indonesia, pendidikan Islam sudah mulai tumbuh meskipun masih individual. Maka dari itu pendidikan Islam di Indonesia dimulai oleh para tokoh agama dengan mendekati masyarakat secara persuasif dan memberikan pengertian tentang dasar-dasar agama Islam yang memanfaatkan lembaga-lembaga masjid, surau, dan langgar mulailah secara bertahap berlangsung pengajian umum mengenai tulis baca al-Qur'an serta wawasan keagamaan. Namun demikian, pelembagaan khusus untuk pelaksanaan pendidikan bagi umat Islam di Indonesia baru terjadi dengan pendirian pesantren. ${ }^{19}$

18 Malik A. Fadjar, Reorientasi Pendidikan Islam, (Jakarta: Fajar Dunia.1999), h. 64

${ }^{19}$ Hasan Langgulung, Beberapa Pemikiran Tentang Pendidikan Islam, (Bandung: al-Ma'arif, 1980), h. 16 
Pendidikan Islam di Indonesia sudah berlangsung sejak masuknya Islam ke Indonesia. Pada tahap awal pendidikan Islam dimulai dari kontakkontak pribadi maupun kolektif antara mubalig (pendidik) dengan peserta didiknya. Setelah komunitas muslim terbentuk di suatu daerah tersebut tentu mereka membangun tempat peribadatan, dalam hal ini masjid. Sesuai dengan gencarnya pembaruan pemikiran Islam yang dicanangkan oleh para pembaharu muslim di berbagai negara sampai juga gaung pembaruan itu di Indonesia. Dalam hal ini, ide-ide pembaruan pendidikan di Indonesia mulai muncul di awal abad ke XX, disebabkan banyaknya orang yang tidak puas dengan sistem pendidikan yang berlaku saat itu. Karenanya ada beberapa sisi yang perlu diperbaharui, yakni dari segi isi (materi), metode, sistem dan manajemen. ${ }^{20}$

Diakui atau tidak, sistem pendidikan yang berjalan di Indonesia saat ini memang adalah sistem pendidikan yang sekular-materialistik. Bila disebut bahwa sistem pendidikan nasional masih mewarisi sistem pendidikan kolonial, maka watak sekular-materialistik inilah yang paling utama, yang tampak jelas pada hilangnya nilai-nilai Islam pada semua proses pendidikan. Pendidikan materialistik memberikan kepada siswa suatu basis pemikiran yang serba terukur secara material serta memungkiri hal-hal yang bersifat non-materi. Disadari atau tidak, berkembang penilaian bahwa hasil pendidikan haruslah dapat mengembalikan investasi yang telah ditanam. Pengembalian itu dapat berupa gelar kesarjanaan, jabatan, kekayaan, atau apapun yang setara dengan nilai materi yang telah dikeluarkan. Agama ditempatkan pada posisi yang sangat individual. Hukum syara' Islam dirasa tidak patut atau tidak perlu dijadikan sebagai standar penilaian sikap dan perbuatan.

Sistem pendidikan yang material-sekuleristik tersebut sebenarnya hanyalah merupakan bagian belaka dari sistem kehidupan bermasyarakat

${ }^{20}$ Dody S. Truna dan Ismatu Ropi, Pranata Islam di Indonesia: Pergulatan Sosial, Politik, Hukum, dan Pendidikan, cet.I, (Ciputat: Logos Wacana IImu, 2002), h. 45 
dan bernegara yang juga sekuler. Dalam sistem sekuler, aturan-aturan, pandangan dan nilai-nilai Islam memang tidak pernah secara sengaja digunakan untuk menata berbagai bidang, termasuk bidang pendidikan. Agama Islam, sebagaimana agama dalam pengertian Barat, hanya ditempatkan dalam urusan individu dengan tuhannya saja. Maka, di tengahtengah sistem sekuleristik tadi lahirlah berbagai bentuk tatanan yang jauh dari nilai-nilai agama. Yakni tatanan ekonomi yang kapitalistik, perilaku politik yang oportunistik, budaya hedonistik, kehidupan sosial yang egoistic dan individualistik, sikap beragama yang sinkretistik, serta paradigma pendidikan yang materialistik. ${ }^{21}$

Fenomena merebaknya pemikiran sekularis, pluralis dan liberalis di sejumlah lembaga pendidikan Islam bukanlah hal baru. Sejak awal berdirinya, berbagai aliran pemikiran dan paham ideologi tumbuh subur di dalamnya. Tak hanya terjadi di lembaga pendidikan formal, pemikiran tersebut pun telah merasuk ke pondok pesantren. KH Khalil Ridwan pernah menyampaikan peringatannya yang dimuat di "surat pembaca" Harian Republika (27/3/2006) terkait dengan adanya upaya infiltrasi paham sekularisme-liberalisme ke pondok-pondok pesantren yang dilakukan oleh lembaga pengasong ide liberal: International Center for Islam and Pluralism (ICIP). Lembaga ini didanai oleh The Asia Foundation (TAF). Fakta lain, pada 18-28 September 2002, Institute for Training and Development (ITD), sebuah lembaga Amerika, telah mengundang 13 pesantren 'pilihan' di Indonesia (dari Jawa, Madura, Sumatera, Kalimantan, dan Sulawesi) untuk berkunjung ke AS. Agenda ini terkait dengan kampanye liberalisasi pemikiran Islam ke pondok pesantren.

Berbagai kasus pemikiran yang terjadi ternyata tidak terlepas dari upaya westernisasi (pem-Barat-an) negeri-negeri Islam yang dipromotori oleh Amerika, Inggris dan sekutunya. Melalui badan dunia PBB dan

${ }^{21}$ Lihat Abdul Halik, "Paradigma Pendidikan Islam dalam Transformasi Sistem Kepercayaan Tradisional." AL-ISHLAH: Jurnal Pendidikan Islam 14.2 (2016). 
yayasan-yayasan internasional, Barat beserta para kapitalis melancarkan serangannya dengan menyusun program dan strategi liberalisasi pendidikan ke negara target maupun langsung ke lembaga pendidikan, termasuk lembaga pendidikan Islam. Konspirasi liberalisasi pendidikan ini merupakan kelanjutan dari upaya Barat menghapuskan peradaban Islam dan mencegah tegaknya kembali syariah. Selanjutnya Barat berharap akan tetap mampu menancapkan hegemoninya di dunia, termasuk di negeri-negeri Islam.

Dalam upaya liberalisasi pendidikan Islam, termasuk pesantren di Indonesia, dengan gencar Barat melancarkan modus berikut : ${ }^{22}$

Pertama: intervensi kurikulum pendidikan Islam dan pondok pesantren. Kurikulum sebagai panduan untuk membentuk produk pemikiran dan perilaku pelajar/mahasiswa menjadi salah satu sasaran intervensi. Kurikulum bidang akidah, konsep wahyu maupun syariah Islam menjadi obyek liberalisasi yang tersistemkan. Liberalisasi akidah Islam diarahkan pada penghancuran akidah Islam dan penancapan paham pluralisme agama yang memandang semua agama adalah benar. Liberalisasi konsep wahyu ditujukan untuk menggugat otentisitas (keaslian) al-Quran Mushaf Utsmani dan as-Sunnah. Adapun liberalisasi syariah Islam diarahkan pada penghancuran hukum-hukum Islam dan penghapusan keyakinan umat terhadap syariah Islam sebagai problem solving bagi permasalahan kehidupan manusia.

Dalam upaya intervensi kurikulum ini, The Asia Foundation (TAF) tercatat sebagai pengucur dana untuk reformasi kurikulum pendidikan kewarganegaraan di empat universitas Islam yang membawahi 625 institusi dan kurang lebih 215.000 pelajar. Sejak tahun 2000, TAF bekerjasama dengan beberapa Perguruan Tinggi Agama Islam di Indonesia mengubah kurikulum untuk memperkuat reformasi demokrasi dan liberalisasi. Di samping intervensi kurikulum pendidikan Islam di Indonesia, Barat pun berupaya mengintervensi kurikulum pondok-pondok pesantren dengan

${ }^{22}$ Muhamad Shidiq Al-Jawi. Pendidikan Di Indonesia, Masalah dan Solusinya. Artikel. www.khilafah1924.org 
kucuran dana 157 juta dolar AS lewat Kementerian Agama RI. Menyikapi hal itu, KH Kholil Ridwan dari Badan Kerjasama Pondok Pesantren Indonesia (BKSPPI) menyerukan kepada para kiai pesantren agar menolak pemberian dana Amerika sebesar Rp 50 juta lewat Kementerian Agama kalau disuruh mengubah kurikulum pesantren model mereka.

Kedua: bantuan pendidikan dan beasiswa kepada lembaga pendidikan Islam dan pelajar/mahasiswa di Indonesia. The Asia Foundation telah mendanai lebih dari 1000 pesantren untuk berpartisipasi dalam mempromosikan nilai-nilai pluralisme, toleransi dan masyarakat sipil dalam komunitas sekolah Islam di seluruh Indonesia. Tahun 2004, TAF memberikan pelatihan kepada lebih dari 564 dosen yang mengajarkan pelatihan tentang pendidikan kewarganegaraan yang kental dengan ide liberalis-sekular untuk lebih dari 87.000 pelajar. Fakta lain, AS dan Australia juga membantu USD 250 juta dengan dalih mengembangkan pendidikan Indonesia. Padahal, menurut sumber diplomat Australia yang dikutip The Australian (4/10/2003), sumbangan tersebut dimaksudkan untuk mengeliminasi 'madrasah-madrasah' yang menghasilkan para 'teroris' dan ulama yang membenci Barat.

Ketiga: pembentukan jaringan intelektual Muslim yang menyuarakan liberalisasi pemikiran Islam. Jaringan intelektual ini diwakili oleh Jaringan Liberal yang berlabelkan Islam, bekerjasama dengan para intelektual, penulis dan akademisi dalam dan luar negeri. Jaringan ini gencar menyuarakan kampanye dan pengopinian reorientasi pendidikan Islam menuju pendidikan Islam yang pluralis melalui berbagai media propaganda.

Target akhir dari upaya liberalisasi pendidikan Islam dan pondok pesantren di Indonesia adalah liberalisasi pemikiran Islam dan menciptakan Muslim moderat yang pro Barat. Dari merekalah selanjutnya agenda liberalisasi pemikiran Islam akan disebarluaskan di tengah-tengah masyarakat. Sasaran pembentukan Muslim moderat diprioritaskan dari kalangan intelektual Muslim dan ulama. Alasannya, karena intelektual Muslim dinilai memiliki peran strategis, baik dalam menentukan kebijakan pemerintah maupun peluang memimpin masyarakat; sedangkan ulama 
dinilai memiliki pengaruh di tengah-tengah masyarakat akar rumput, di samping sebagai pelegitimasi hukum terhadap berbagai fakta baru yang berkembang. Dari sini dapat dipahami mengapa Barat begitu getol mengontrol dan mengarahkan sistem pendidikan Islam pencetak para intelektual Muslim dan ulama.

\section{KESIMPULAN}

Tantangan pendidikan Islam saat ini jauh berbeda dengan tantangan pendidikan Islam,sebagaimana yang terdapat pada zaman klasik dan pertengahan. Baik secara internal maupun eksternal, tantangan pendidikan Islam di zaman klasik dan pertengahan cukup berat, namun secara psikologis dan ideologis lebih mudah diatasi. Secara internal, umat Islam pada masa klasik masih fresh (segar). Masa kehidupan mereka dengan sumber ajaran Islam, yakni Al-Quran dan sunnah masih dekat, serta semangat militansi dalam berjuang memajukan Islam juga masih amat kuat. Sedangkan secara eksternal, umat Islam belum menghadapi ancaman yang serius dari negara-negara lain, mengingat keadaan negara-negara lain (Eropa dan Barat) masih belum bangkit dan maju seperti sekarang.

Adanya dikotomi antara pendidikan agama (Islam) dan pendidikan umum yang belum terjembatani sampai saat ini secara real mengantarkan posisi pendidikan agama selalu menjadi pelengkap mata kuliah/pelajaran lainnya di lembaga pendidikan umum. Upaya untuk menempatkannya ke dalam ranah analisis perlu segera diwujudkan mengingat hal itu jarang dilakukan sebelumnya. Masuknya sistem metodologi ala Barat juga harus mendapat perhatian khusus agar tidak menghasilkan anak didik yang bersifat "sekuler" dan kehilangan nilai-nilai etika Islam.

\section{REFERENSI}


Aly, Hery Noer dan Munszier Suparta. Pendidikan Islam Kini dan Mendatang. Cet. I; Jakarta: CV. Triasco, 2003.

Azizy, Qodri. Pendidikan (Agama) Untuk Membangun Etika Sosial: Mendidik Anak Sukses Masa Depan: Pandai dan Bermanfaat. Cet. 1; Semarang: Aneka Ilmu, 2002.

Fadjar A. Malik. Reorientasi Pendidikan Islam, Jakarta : Fajar Dunia, 1999. Halik, Abdul. "Dialektika Filsafat Pendidikan Islam (Argumentasi dan Psikologi)." Istiqra' 1.1 (2013): 22-28.

Halik, Abdul. "Paradigm of Islamic Education in the Future: The Integration of Islamic Boarding School and Favorite School." Information Management and Business Review 8.4 (2016): 24-32.

Halik, Abdul. "Paradigma Pendidikan Islam dalam Transformasi Sistem Kepercayaan Tradisional." AL-ISHLAH: Jurnal Pendidikan Islam 14.2 (2016).

Hasan, IqbaI. Analisis Data Penelitian Dengan Statistik. Jakarta: Bumi Aksara, 2008.

Kaelan. Metode Penelitian Agama Kualitatif Interdisipliner. Yogyakarta: Paradigma, 2010.

Kartono, Kartini. Pengantar Metodologi Research. Bandung: ALUMNI, 1998.

Maarif, A .Syafii. "Keutuhan dan Kebersamaan dalam Pengelolaan Pendidikan Sebagai Wahana Pendidikan Muhammadiyah”, makalah disampaikan pada Rakernas Pendidikan Muhammadiyah, di Pondok Gede, Jakarta, 1996.

Noor, Juliansyah. Metode Penelitian: Skripsi, Tesis, Desertasi, dan Karya IImiah. Jakarta: Kencana, 2011.

Sewang, Anwar, and Abdul Halik. "Learning Management Model of Islamic Education based on Problem: A Case Study of the Tarbiyah and Adab Department of IAIN Parepare." Journal of Talent Development and Excellence 12.1 (2020): 2731-2747. 
Steenbrink, Karel A., Pesantren Madrasah Sekolah Pendidikan Islam dalam Kurun Moderen, Cet. Kedua, Jakarta: LP3ES, 1994.

Sudiro, M. Irsyad., Pendidikan Agama dalam Masyarakat Modern, Seminar dan Lokakarya Nasional Revitalisasi Pendidikan Luar Sekolah dalam Masyarakat Modern, Cirebon, Tanggal, 30 Agustus - 1 September 1995.

Suroyo, Perbagai Persoalan Pendidikan; Pendidikan Nasional dan Pendidikan Islam di Indonesia, Jurnal Pendidikan Islam, Kajian tentang Konsepo Pendidikan Islam, Problem dan Prospeknya, Volem 1 Tahun 1991, Fakultas Tarbiyah IAIN, Yogyakarta, 1991.

Suryabrata, Sumadi. Metodologi Penelitian. Jakarta: PT. Raja Grafindo Persada, cet. Ke-11, 1998.

Truna, Dody S. dan Ismatu Ropi. Pranata Islam di Indonesia: Pergulatan Sosial, Politik, Hukum, dan Pendidikan. Cet. I; Ciputat: Logos Wacana Ilmu, 2002.

Undang-undang RI Nomor 20 tahun 2003, Jakarta: Sinar Grafika, 1993

Usa, Muslih, ed., Pendidikan Islam di Indonesia: Antara Cita dan Fakta, Yogyakarta: Tiara Wacana, 1991.

Usri, Usri. "Kontribusi Pendidikan Islam Menuju Indonesia Maju." $A L$ ISHLAH: Jurnal Pendidikan Islam 17.2 (2019): 201-216.

Wasim, Alef Theria, dkk (ed), Harmoni Kehidupan Beragama: Problem, Praktik dan Pendidikan, Oasis Publisher: Yogyakarta, 2005 